\title{
LA POLÍTICA DE INMIGRACIÓN EN LA UNIÓN EUROPEA
}

\section{Desde tres claves}

\author{
Ángeles Solanes Corella \\ Grupo de Estudios sobre Ciudadania, Inmigración y Minorias. \\ Universitat de València
}

ABSTRACT The European Union's immigration policy regarding the control and management of migratory flow, can be seen from many viewpoints. Of these, three are of particular interest. Firstly, the economic aspect, which is based on reducing the figure of the immigrant to a worker, taking into account the conditions and protection of the European Community's employment market. Secondly, the defensive aspect, which emphasises the need to secure frontiers vulnerable to immigrant migration, in order to ensure both security and law and order. Lastly, the social aspect, which focuses on the aim for European homogeneity, a reference point for the implementation of this policy and for the need to integrate immigrants. These three key aspects are essential for us to understand, analyse and question the complex reality of migration to Europe and the legal-political treatment it receives.

KEY WORDS European Union, Immigration Policy, Economic, Defensive and Social Aspects.
RESUMEN La política de inmigración de la Unión Europea, relativa al control y la gestión de los flujos migratorios, puede abordarse desde múltiples perspectivas. De ellas tres me parecen especialmente interesantes. En primer lugar la dimensión económica, que se asienta sobre la reducción del inmigrante a la figura de trabajador, atendiendo a las condiciones y protección del mercado comunitario de empleo. En segundo lugar, la orientación defensiva que pone en evidencia la exigencia de blindar las fronteras ante la interpretación de la inmigración desde una visión de seguridad y orden público. Por último, el enfoque social, que incide en la pretendida homogeneidad europea que se toma como referencia en la articulación de esta política y en la necesidad de integración de los inmigrantes. Estas tres claves nos aportan aspectos esenciales para comprender, analizar y cuestionar la compleja realidad de las migraciones hacia Europa y el tratamiento político-jurídico de las mismas.

PALABRAS CLAVE Unión Europea, Politica de Inmigración, Aspectos Económicos, Defensivos y Sociales.

\section{Un breve repaso de la política de inmigración en la Unión Europea}

La cooperación entre distintos Estados europeos, a medidos de los años 80 , surgida de la voluntad marcadamente economicista de crear un mercado interior común, en el seno de la entonces denominada Comunidad Económica Europea, pronto se relacionó con la necesidad de protección de las fronteras exteriores y los flujos migratorios. Así en 1985 con la firma del acuerdo Schengen (en el marco del grupo TRE$\mathrm{VI}^{1}$ ) se afianzó la conexión entre inmigración y delito, la cual adquirió una especial relevancia con la firma del Convenio de aplicación de dicho acuerdo en $1990^{2}$. El denominado espacio Schengen nació con un claro objetivo: la supresión física de las fronteras sin merma de la seguridad interna. Para ello se tomaron diversas medidas tales como la modificación del sistema fronterizo (con la eliminación de fronteras hacia el interior y el mantenimiento de controles con terceros
Estados no comunitarios), el tratamiento común a las personas que cruzan la frontera desde un tercer Estado, y el fortalecimiento de las medidas de seguridad con la coordinación de las administraciones encargadas del control fronterizo ${ }^{3}$.

En 1992 con la firma del Tratado de la Unión Europea en Maastricht se consagró la estructura de los tres pilares, considerando como ámbitos de interés común en el tercer pilar el asilo, el cruce de personas por las fronteras exteriores y las prácticas de controles, la política de inmigración y ciertos aspectos de la política relativa a los nacionales de terceros Estados ${ }^{4}$. El propio Tratado de la Unión preveía su reforma en 1996. Asi se llegó a la Conferencia Intergubernamental de dicho año y como fruto de la misma se adoptó el Tratado de Amsterdam de 2 de octubre de 1997, que constituye el verdadero punto de inflexión a partir del cual comienza a hablarse propiamente de política de inmigración europea. 
El Tratado de Amsterdam que entró en vigor en 1999, contemplaba como objetivo de la Unión la creación de un espacio de libertad, seguridad y justicia, estableciendo una clara relación entre la libre circulación de personas y el control de los flujos migratorios, como forma de garantizar dicho espacio. El acuerdo y el convenio de aplicación de Schengen, asi como el resto de previsiones relativas al cruce de las fronteras exteriores y al acceso al territorio de Estados miembros de la Unión (con excepciones como la de Dinamarca, Irlanda e Inglaterra), se incluyeron en el Tratado de la Unión Europea, es decir, comenzó la comunitarización de la política de inmigración.

Este Tratado fijó un plazo de 5 años (hasta el 1 de mayo de 2004) para conseguir la plena comunitarización de dicha política. A partir de este momento la creación del mencionado espacio de libertad, seguridad y justicia, y la cuestión de la inmigración ha sido un tema recurrente tanto en los distintos consejos europeos como en las comunicaciones, recomendaciones y directivas de la Unión ${ }^{5}$. Tras la expiración de dicho término muchos de los objetivos quedan pendientes, aunque se han conseguido ya algunos logros 6 .

En todo caso, la comunitarización llevada a cabo por el Tratado de Amsterdam en relación a la política de inmigración puede calificarse como incompleta o hibrida, en la medida en que refuerza el papel de los Estados. En la política de inmigración y respecto de la residencia, los Estados miembros no pueden verse limitados a mantener o introducir disposiciones nacionales, siempre que sean compatibles con el Tratado y los acuerdos internacionales. Es decir, a través de los actos del Consejo de la Unión Europea no se podrá constreñir a los Estados en estas materias más de lo que lo hacen los tratados que en este aspecto pueden considerarse el límite máximo (La Calle 2002, 93).

Por tanto, a pesar de los notables esfuerzos, y los indudables avances, para coordinar la política comunitaria europea 7 , mejorando los sistemas de información, vinculando las cuestiones relativas a las migraciones con la relaciones con terceros Estados, en especial con los de origen, etc., las directrices marcadas por la Unión en materia de inmigración surgen fuertemente condicionadas por la voluntad de los respectivos Estados ${ }^{8}$.

Es decir, los discursos y la prácticas sobre la inmigración en el espacio comunitario están atravesados por la propia estructura del Estado, por el pensamiento que en ella subyace, dando lugar a resoluciones comunitarias de mínimos (Gil Araújo 2005, 49).

En cualquier caso, conviene tener en cuenta como señala Sassen $(2001,75)$ que la inmigración cumple la doble caracteristica de ser objeto central e instrumento en el contexto de la renacionalización del discurso político, y al mismo tiempo, objeto de las prácticas y politicas gubernamentales. Por tanto, es un ámbito fundamental para analizar la relación entre la idea de soberanía como control sobre quienes entran y las limitaciones de los Estados para desarrollar una política sobre esta cuestión. La inmigración es, en definitiva, una cuestión estratégica para desmontar las teorías sobre la soberanía.

El Tratado Constitucional de la Unión Europea, en su artículo 267, contempla la elaboración de una ley o ley marco europea para la regulación del control fronterizo, la expedición de visados, las condiciones de ingreso, estancia y expulsión, y la definición de los derechos y las medidas de integración de los nacionales de terceros paises que residan legalmente en el espacio comunitario. Un marco semejante se propone también en relación al asilo. Esta ley es, de momento, un mero proyecto cuya concreción depende de múltiples factores.

Mientras tanto, de los distintos instrumentos destinados a marcar las directrices para la articulación de la política migratoria común, pueden extraerse una serie de pautas que interpretaré en tres claves: económica, defensiva y social, que nos aportan lo que hasta ahora han sido los principios inspiradores de la politica y la normativa en materia de inmigración en la Unión Europea.

\section{Clave Económica}

Una de las reducciones más evidentes y constantes en las medidas destinadas a gestionar la inmigración en el espacio europeo es aquella que circunscribe la figura de inmigrante a la de trabajador ${ }^{9}$. Los movimientos migratorios hacia la Unión Europea tienden a limitarse atendiendo a la demanda de fuerza de trabajo, es decir, los nacionales de terceros Estados que deseen entrar en territorio comunitario legalmente, salvo circunstancias excepcionales (cada vez más acotadas y limitadas), y como inmigrantes económicos, verán reconducido su estatuto jurídico al trabajo que desempeñen. Apenas se incide en las causas del proceso que han provocado la existencia de un importante número de personas dispuestas a emigrar, 
ni se actúa sobre los diversos mecanismos que generan puestos de trabajo disponibles para los inmigrantes, en el mercado legal o en la economía sumergida, a pesar de que se trata de aspectos conocidos y cuestionados, como si la inmigración fuera un tema independiente de estas cuestiones ${ }^{10}$.

\subsection{Preferencia comunitaria y protección del mercado laboral}

En general, antes de que un nacional de un tercer pais, pueda ser admitido en la Unión, los Estados han de demostrar la necesidad económica para que proceda legalmente dicha entrada, es decir, deben comprobar que nadie del mercado laboral interno puede ocupar el puesto en cuestión. Esta es la base primordial para la articulación de los denominados contingentes 0 cuotas anuales ${ }^{11}$.

El principio de control que inspira los contingentes implica, en la práctica, una lógica de gestión de los flujos migratorios en función de las necesidades básicamente laborales de cada momento, que no siempre es posible ni eficaz. Obviamente, como punto de partida, la selección cuantitativa de los inmigrantes que pueden tener acceso a un pais es discriminatoria cualquiera que sea el criterio que se aplique:

a) En el caso de las cuotas por nacionalidad, nos encontramos ante una discriminación del inmigrante por razón de origen. Esta opción además de crear desigualdades entre los propios extranjeros puede ser incluso contraproducente para los inmigrantes digamos elegidos si se relaciona directamente, con la firma de tratados bilaterales con los Estados de origen en cuestión, que aceptan condiciones de repatriación rápida a cambio de que se aumente la cuota reservada a sus nacionales en el contingente anual ${ }^{12}$.

b) En el caso de las cuotas por sectores de actividad, como es el caso de los contingentes españoles, estamos ante una discriminación en el acceso al empleo que condena a los inmigrantes a ocupar los sectores laborales desechados por la población autóctona. Esta alternativa presupone un conocimiento exhaustivo de las necesidades del mercado de trabajo nacional y una programación a priori que muchas veces acaba teniendo importantes desajustes con las necesidades reales.

En ambos casos la concepción del inmigrante como trabajador, mano de obra barata, llamado a cubrir las necesidades laborales de la sociedad de acogida, está presente.
Esta prevención junto con la preferencia comunitaria ${ }^{13}$ entendida como prioridad de los nacionales, los comunitarios y no comunitarios residentes permanentes en un Estado miembro, frente a los nacionales de terceros países recién llegados, cierra el círculo que canaliza la ocupación de los inmigrantes económicos en los nichos laborales más precarios. Como recuerda la Comisión (COM 2004, 811 final) al abordar la gestión de la inmigración económica, a partir de 2006 los residentes de larga duración tendrán preferencia sobre los recién llegados al Estado miembro de residencia y podrán trasladarse a un segundo Estado también miembro para estudiar, trabajar o con otros fines (de acuerdo con lo establecido en la Directiva 2003/109/CE del Consejo), reforzando así las estrictas condiciones a las que se ven sometidas los recién llegados en el acceso al mercado laboral.

Estas políticas migratorias basadas en elecciones cuantitativas y selectivas en el intento de querer encerrar en categorias y cifras la realidad que regulan, se ven atrapadas en una inmensa burocracia de forma que la ilusión de conseguir el control cae en el cálculo arbitrario (Costa-Lascoux 1999, 50).

Por otra parte, se olvida a menudo desde las medidas puestas en marcha en los respectivos ámbitos nacionales de los Estados, los análisis que la Unión proporciona en cuanto al carácter económicamente positivo de la inmigración.

En este sentido el primer informe anual sobre migración e integración (COM, 2004, 508 final), señala el carácter optimista de la teoria económica en cuanto al impacto de la inmigración, puesto que la considera beneficiosa para el bienestar general. Respondiendo a las críticas, enunciadas desde planteamientos como los de Sartori (2001,120-121), en virtud de las cuales los inmigrantes suponen una carga para el Estado de Bienestar ${ }^{14}$, generando unos costes no compensados por el pago de impuestos que realizan, el mencionado informe mantiene que la integración de los inmigrantes puede mejorar las finanzas públicas.

Los inmigrantes, respecto a las premisas del Estado de Bienestar que implican un núcleo estable de población que comparte interdependencias e intereses respecto a las generaciones pasadas y futuras, son vistos como un potencial peligro. Su caracteristica renta y movilidad, normalmente menor y mayor respectivamente que la de los autóctonos, conlleva una doble preocupación para la población nativa: por una parte, siendo personas en condiciones económicas más precarias tienen más posibilidades de acudir a las 
prestaciones que el Estado les ofrece; por otra, el hecho de que su estancia en el país receptor pueda ser meramente temporal pone en cuestión la mencionada interdependencia necesaria para que el sistema funcione ${ }^{15}$.

Sin embargo, el informe señala que para que la mejora que la inmigración conlleva sea posible, más teniendo en cuenta la dificultad de realizar un cálculo fiable de la contribución fiscal neta de los inmigrantes, debe permitirse el acceso al mercado de trabajo. Es decir, la pirámide de edad de los inmigrantes es, en principio, beneficiosa a las finanzas públicas, puesto que se trata de jóvenes en edad laboral que presentan un mayor potencial para pagar impuestos que para recibir transferencias y servicios públicos individuales (en una proporción que es superior a la media). Sin embargo, si el empleo es bajo, por las múltiples dificultades que encuentran especialmente en el acceso al mercado laboral (los recién llegados, especialmente), se contrarresta el posible impacto fiscal positivo que podria derivar de su estructura de edad. Así, sólo en los Estados miembros de la Unión en los que el nivel de empleo de los migrantes excede al de la población autóctona, podemos encontrar un impacto fiscal neto positivo de la inmigración.

Por tanto, no puede afirmarse categóricamente que los inmigrantes supongan, en líneas generales, un lastre económico para el Estado de Bienestar difícil de remontar, aunque pueda ser cierto, como desde la Unión se ha mantenido, que existe un aumento en la dependencia de bienestar especialmente entre los solicitantes de asilo a los que no se permite trabajar de ninguna manera o sólo de forma muy limitada ${ }^{16}$.

Este tipo de afirmación, nos llevaria al análisis de una cuestión, la del asilo y el refugio, que escapa a este trabajo, pero que puede ser reconducida a la idea básica, en lo que ahora incumbe, de que los extranjeros que tienen vetado el acceso al mercado laboral (formal de empleo), pueden ser vistos como potenciales cargas para el sistema de bienestar. Lo cierto es que éstos generan importantes ingresos en la economía sumergida, otra forma implicita de riqueza para los Estados, que no existe de forma gratuita o desinteresada.

\subsection{La necesidad de nuevos esclavos}

Ciertamente un claro interés político y económico marca los puestos de trabajo que ocupan los inmigrantes en los Estados de la Unión y, desde la misma perspectiva, se consiente que un importante número de extranjeros no puedan acceder al mercado formal de empleo, quedando asi privados de derechos y convirtiéndose en los nuevos esclavos.

En palabras de Lynch $(2005,66)$ estos inmigrantes tienen como caracteristica el hecho de permanecer ocultos, denegados o soslayados, siendo diseminados fácilmente por el aparato productivo local, de modo que sólo ante las circunstancias más extremas cuando se dan episodios xenófobos (como el Ejido en España ${ }^{17}$ ) o catástrofes (como la del buque Tampa ${ }^{18}$ ) se hace patente su presencia. No aparecen reflejados en las estadisticas oficiales porque representa nuestra fuerza de trabajo esclavizada, o lo que es lo mismo, la cesión de todos los principios de derecho en los que hemos asentado nuestros modernos Estados democráticos.

Como ya he señalado en otras ocasiones (Solanes 2003, 128131), las normativas de extranjería e inmigración fuertemente restrictivas en los sistemas de acceso y permanencia en el ámbito de la legalidad influyen directamente en la proliferación de inmigrantes en situación irregular, del mismo modo, que la subsistencia de la economía sumergida legalmente consentida es el verdadero efecto llamada que anima a nuevos extranjeros a emigrar hacia los Estados de la Unión.

En la génesis de buena parte de los procesos extraordinarios de regularización que se han producido en los últimos años especialmente en los países de la Europa del Sur ${ }^{19}$, encontramos, a mi juicio, un factor desencadenante, una causa común: la legislación represiva (Terray 1999, 21):

1 El primer requisito para que acabe siendo necesario adoptar una medida extraordinaria de regularización es fomentar la vulnerabilidad administrativa, lo cual se consigue rápidamente con una norma represiva que primero impida o restrinja la entrada en territorio nacional por la vía legal, y después dificulte la permanencia en esa legalidad de los que consiguieron salvar los primeros obstáculos en el momento de la entrada. La fragilidad administrativa, fruto en buena medida del vínculo indisoluble entre autorización de trabajo y de residencia, convierte al inmigrante en el blanco perfecto de la explotación empresarial, del arrendador de su vivienda o de cualquiera que con él se relacione.

Ese proceso de vulnerabilidad del inmigrante no podría alcanzarse sin la voluntad, implícita o explícita, del Estado en el que éste se encuentra y la plasmación de la misma en las leyes de extranjería e inmigración. La gradación de esa 
vulnerabilidad es otra de las virtudes que al Derecho corresponde. De este modo se completa la jerarquía legal de la exclusión en la que el extranjero, por el mero hecho de serlo, ocupa un nivel inferior al ciudadano y a partir de ahi se sitúa en un lugar más o menos privilegiado en virtud de su situación administrativa.

2 Un segundo requisito, dentro del marco de la legislación represiva, contribuirá a hacer necesario un proceso de regularización extraordinaria: la aplicación selectiva de la ley. Así, la norma al mismo tiempo que propicia la situación de vulnerabilidad de determinados colectivos de extranjeros, debe permitir que los empresarios les empleen y cubran con ellos sus necesidades ${ }^{20}$. Como acertadamente señala Terray $(1999,23)$ sin legislación represiva no tiene sentido hablar de fragilidad administrativa que permita la explotación de los inmigrantes en situación irregular, pero sin aplicación débil de esta legislación, tampoco habría trabajadores que sufrieran esa explotación.

El hecho es que en las normativas de extranjeria de los Estados de la Unión existen preceptos dedicados a la sanción de los empresarios que aprovechan la situación de necesidad de los inmigrantes, artículos que intentan restablecer la simetría entre los distintos sujetos a los que la ley se dirige. El problema, como ocurre en el caso español, es que no se aplican de igual forma: por cada detención o sanción de un empresario por explotación de inmigrantes en situación irregular ¿cuántas expulsiones (de inmigrantes que trabajaban para él) se han producido sin que el empresario se haya visto afectado?. En estos casos, no basta con señalar que existe una aplicación débil y modulada de la ley, sino que es necesario destacar que nos encontramos ante una tolerancia de hecho, en virtud de la cual, las sanciones a los empresarios son más bien excepcionales y no suelen afectar a los verdaderos responsables.

La economia sumergida en la que se insertan los inmigrantes se sostiene con la complicidad, aunque sea implícita, de las instituciones desde el ámbito local hasta el nacional, olvidando que precisamente la represión de la misma es uno de los puntos focales de las politicas reguladoras de los flujos migratorios ${ }^{21}$. Asi Sciortino $(1997,70$ y 1999, 21-40) llega a afirmar que los controles en las fronteras para evitar la entrada de clandestinos tienen menor importancia que las inspecciones en los lugares de trabajo y que las sanciones aplicables a los empresarios que infringen la ley, al explotar a inmigrantes en situación irregular, son más importantes que las expulsiones en sí.

Parece evidente, por tanto, la necesidad de potenciar la estricta aplicación de la ley para quienes se benefician de la vulnerabilidad que ésta genera, y al mismo tiempo conseguir la flexibilización de las legislaciones de extranjería e inmigración para favorecer el acceso a la legalidad. Este es un camino necesario para acabar con la proliferación de los nuevos esclavos. De lo contrario, ante la falta de oportunidades legales para quienes tras haber tenido una autorización de residencia y trabajo por diversos motivos (como el transcurso de los plazos legales para solicitar la renovación o la imposibilidad de acreditar los medios de subsistencia en el momento que se les exige), se ven abocados a vivir al margen de la normativa, la única alternativa real y, por otra parte cotidianamente común, es la de obtener ingresos en el mercado informal de trabajo generando, al mismo tiempo, importantes beneficios en la economía sumergida (Ambrosini 1998, 124-131 y 2001, 47-63) que no revierten en los sujetos que los producen.

Los inmigrantes clandestinos o irregulares saben que su salario será inferior al de los extranjeros en situación regular y al de los nacionales, conocen también que deberán afrontar condiciones de vida y de trabajo muy duras, que en la practica les convertirá en auténticos esclavos. La certeza de que serán empleados y pagados, pudiendo mandar remesas a sus familias, es la que les anima. Una seguridad de empleo en la economía sumergida que se alimenta con la complicidad de la ley que no se decide a combatir la actuación ilegal de los empresarios, aunque se recoja en las normas, y que no ofrece ninguna salida a la explotación. La perspectiva de una regularización se presenta, casi siem-

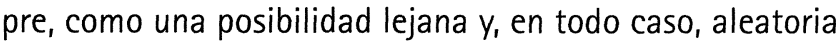
y no el motivo principal que alimenta la partida del pais de origen, (Terray 1999, 33) 22 .

Esta voluntad implícita de que exista un número de extranjeros al margen de la legalidad, coloca a los inmigrantes en una doble situación de la que es difícil salir sin alternativas legales:

1 Victimización, porque siendo la normativa vigente la que crea callejones sin salida que conducen a la clandestinidad y benefician a las redes mafiosas, 0 a la irregularidad sobrevenida, es el inmigrante el que una y otra vez se convierte en el destinatario último de la sanción desproporcionada respecto a la infracción cometida 23 . 
2 Criminalización, porque colocando a la persona extranjera en situaciones extremas de desesperación es como se consigue que ésta se decida a cruzar al ámbito de lo ilegal.

Más difícil es todavía la situación de los extranjeros para los que la legislación no contempla la posibilidad de que salgan de la situación de irregularidad en la que se encuentran, ni siquiera con procesos extraordinarios. Me refiero a los extranjeros con orden de expulsión firme no ejecutada. En casos como el español, es bastante frecuente que tras finalizar la tramitación del expediente de expulsión ésta, por distintos motivos materiales, de falta de presupuesto etc., no pueda llevarse a la práctica. Con independencia de que en estos supuestos pueda dictarse la medida excepcional de internamiento en centros no penitenciarios como plantea Sagarra i Trias $(2002,95)$, lo cierto es que el extranjero en tal situación, si no es expulsado o hasta que lo sea, permanece en España en un status de total precariedad, como la del resto de irregulares, agravada por la nula perspectiva de regularización. Estos extranjeros mantienen buena parte de la economía que la política de inmigración implicitamente alimenta.

En cualquier caso, a pesar de su vital importancia, la perspectiva económica, debe tener también en cuenta otros factores fundamentales en el establecimiento de directrices en el ámbito comunitario. Estrechamente relacionada con esta dimensión, especialmente en lo que a proliferación de inmigrantes en situación irregular se refiere, encontramos la segunda clave a tener en cuenta en la política migratoria de la Unión.

\section{Clave defensiva}

La obsesión de la fortaleza asediada, como la denomina Costa-Lascoux $(1999,45)$, ha hecho que en todas las normativas de los Estados comunitarios proliferen, en relación a los extranjeros inmigrantes, medidas de control y retención administrativas, sanciones penales contra los extranjeros y las personas que les ayudan, procesos simplificados o abreviados, en definitiva acelerados, para las expulsiones, etc ${ }^{24}$ Todo ello con una gestión informatizada interconectada de la información y los datos de los extranjeros (Solanes y Cardona 2005, 134-141), con la clara finalidad de defenderse frente al enemigo común.

Como señalaba anteriormente, desde que el tratado de mencionado espacio de libertad, seguridad y justicia, en un intento de dar respuesta a los desafios de la integración europea, éste siempre ha estado asociado a la comunitarización de la política de inmigración 25 .

Los mecanismos de control o defensa frente a la inmigración que los distintos países europeos han puesto en marcha en los últimos años se articulan tanto desde la perspectiva externa como la interna, limitando la cuestión a un número máximo de admisibles sin tener en cuenta otros aspectos indirectos del control (Brochmann 1999, 12-19):

1 En cuanto al control externo, antes de que el potencial inmigrante llegue al pais receptor, con medidas como la vigilancia policial de las fronteras, los visados, la responsabilidad de las compañias de transporte en el traslado de los pasajeros, la legislación contra el tráfico ilegal de personas, las campañas de información en las regiones de potencial emigración y los acuerdos con los paises tanto de origen como de tránsito. En realidad, como señala Brochmann (1999, 304-306) el control más eficaz sería el que reuniese las características de externo y preventivo, traduciéndose en un control de la inmigración en origen que redujese los incentivos para emigrar.

2 En cuanto al control interno, que a su vez puede ser implícito o explícito, las medidas que se articulan son, por ejemplo, la vigilancia interior, la documentación e identificación personal obligatoria, el acceso legalmente delimitado a derechos como el trabajo, la sanidad, la educación, etc., las multas y sanciones a los empresarios que empleen a trabajadores en situación irregular, los mecanismos de repatriación y expulsión, y las amnistias, es decir, los procesos extraordinarios (cada vez más ordinarios) de regularización.

Aunque de estos dos tipos de controles los mecanismos externos deberían ser los preferidos por los países europeos, en la medida en que ofrecen mayores perspectivas de éxito y son menos agresivos para la opinión pública, lo cierto, es que no se renuncia a los segundos como forma de paliar las deficiencias de los primeros: con fronteras que siguen siendo porosas, y acuerdos con los paises de origen que básicamente resultan efectivos en las medidas de retorno o repatriación rápida más que en el gestión de los flujos hacia Europa.

ARBOR CLXXXI 713 MAYO-JUNIO [2005] 81-100 ISSN: 0210-1963 


\subsection{El control de las fronteras}

La política de inmigración sigue caracterizándose por su aislamiento formal respecto a otros procesos de primer orden intimamente ligados a ella, como si pudiera abordarse la cuestión de una forma cerrada y delimitada. Sin embargo, la voluntad de los Estados de vigilar sus fronteras, y de permitir o negar la entrada en sus territorio, no garantiza que éstos sean islas que puedan actuar de forma independiente (Bosniak 1992, 745).

Aún siendo la concreción de las medidas de control interno una cuestión eminentemente nacional, que cada Estado concreta en sus respectivas legislaciones de extranjeria e inmigración, aunque siga para ello pautas comunes europeas, es el control externo, en concreto el de las fronteras, una de las cuestiones básicas que preocupa a la Unión 26 . Puesto que las fronteras exteriores europeas son, obviamente, límites geográficos nacionales, el objetivo común de defensa depende, en buena medida, de la eficacia de los distintos Estados colindantes con paises de potencial inmigración para blindar la entrada a territorio europeo. Para ello existe un claro apoyo de los distintos miembros de la Unión.

Según el Plan para la gestión de las fronteras exteriores de los Estados miembros de la Unión 27 , se pretende conseguir el desarrollo de una política común de gestión integrada de las fronteras exteriores y lograr un marco coherente para una acción común a medio y largo plazo. Con esta finalidad se contempla la posibilidad de acudir al presupuesto comunitario, aunque los recursos económicos de los distintos Estados deben seguir siendo la fuente principal de las inversiones y los gastos previstos, especialmente en lo relativo a equipamientos y recursos humanos. Entre las medidas que contempla dicho plan destaca la creación de redes de funcionarios de enlace de inmigración destinados en terceros paises que son los encargados de establecer y mantener contactos con las autoridades de los paises de origen con la finalidad de contribuir a la prevención y combate de la inmigración ilegal, a la repatriación de los inmigrantes ilegales ${ }^{28}$ y a la gestión de la migración legal, tal como se recoge en el artículo primero del reglamento que ha creado dicha red de funcionarios ${ }^{29}$.

Desde el 2002, los distintos Estados han aunado esfuerzos en la protección de las fronteras externas, en la lucha contra la inmigración ilegal, el contrabando y la trata de seres humanos, consiguiendo resultados como el establecimiento de centros especializados para el desarrollo de un currículum de entrenamiento común, un modelo de análisis e investigación de riesgo integrado y un equipo de vigilancia compartido ${ }^{30}$.

Los instrumentos articulados desde el ámbito público a nivel europeo para proteger las fronteras, con sistemas de información y redes como el SIS, SIRENE y SISNET ${ }^{31}$, se completan desde el sector privado con las medidas de control que se impone a los transportistas en relación a las personas transportadas.

La Directiva 2001/51/CE 32 tiene por objeto perfeccionar el artículo 26 del Convenio de aplicación del Acuerdo de Schengen relativo a la responsabilidad del transportistas y concretar la aplicación de esta disposición como instrumento dentro del dispositivo global de control de los flujos migratorios y de lucha contra la inmigración clandestina, respetando las diferencias de los distintos ordenamientos jurídicos de cada Estado.

Las obligaciones que la Directiva contempla constituyen un catálogo de mínimos ${ }^{33}$, puesto que, no se coarta la libertad de los Estados para establecer obligaciones o sanciones adicionales para los transportistas, tal como ha hecho la legislación española.

La intención de control que la Directiva, y en aplicación de la misma las legislaciones nacionales, pretenden "traspasar" a los transportistas se concreta, básicamente, en una obligación de devolución. El transportista debe devolver al lugar de procedencia a los nacionales de terceros países en tránsito cuando el que debía trasladarlo a su lugar de destino se negara a embarcarlo o cuando las autoridades del Estado de destino le hubieran denegado la entrada y lo hubieran devuelto al Estado miembro por el que ha transitado. En caso de denegación de entrada al transportista le corresponde tanto encontrar los medios para la devolución inmediata, costeándola, como hacerse cargo de los costes de estancia y regreso cuando ésta no sea posible ${ }^{34}$.

Los Estados miembros debian adoptar las medidas necesarias para dar cumplimiento a lo dispuesto en esta Directiva antes del 11 de febrero de 2003. En el caso español, a través de la modificación introducida por la ley 14/2003 se han incorporado estas previsiones europeas.

La Directiva 2004/82/CE ${ }^{35}$ completa la de 2001. Aunque se refiere sólo al transporte por vía aérea, queda claro, que 
los Estados tienen la libertad de mantener o establecer obligaciones adicionales asi como de aplicarlas a otro tipo de transportistas.

La principal obligación que se impone a los transportistas es la de comunicación de la información relativa a las personas que van a transportar cuando lo soliciten las autoridades de control en las fronteras exteriores. La Directiva concreta el tratamiento que recibirá esta información que facilitan los transportistas. Los datos proporcionados, se guardarán en un fichero temporal que, tras la entrada de las personas transportadas, se borrarán en un plazo de 24 horas desde su comunicación, salvo que dichos datos vayan a ser necesarios posteriormente para el ejercicio de las funciones legales de las autoridades encargadas del control de fronteras exteriores. Tanto en este caso como en el supuesto de que los datos personales sean utilizados a efectos policiales, posibilidad que la Directiva de 2004 también admite, se insiste en el respeto a la legislación nacional y a las disposiciones sobre protección de datos de la Directiva 95/46/CE.

Los Estados miembros tienen como plazo para adoptar las medidas necesarias que den cumplimiento a los dispuesto en la Directiva 2004/82/CE, hasta el 5 de septiembre de 2006, teniendo presente que ésta entraba en vigor a principios de septiembre de 2004. En el ordenamiento jurídico español, muchas de las previsiones señaladas se han recogido ya con la ley 14 /2003 y el R. D. 2393/2004, que aprueba el reglamento de desarrollo de la ley $4 / 2000$, modificada por la 8/2000, sobre derechos y libertades de los extranjeros en España y su integración social.

Los esfuerzos aunados del sector público y privado caminan hacia una mayor eficacia del control fronterizo como pieza clave de la perspectiva defensiva de la política migratoria europea, aunque ello suponga importantes costes ${ }^{36}$. Como ha señalado Wihtol de Wenden $(2000,44-46)$ el control de las fronteras implica:

a) Un coste político, porque los Estados no disponen de los medios para luchar radicalmente contra la inmigración clandestina, ni pueden llevar a la práctica las amenazas que anuncian sin poner en peligro sus relaciones diplomáticas con los paises de los que proceden buena parte de los inmigrantes. Además desde la perspectiva política la promesa (muchas veces electoral) de control de la inmigración posteriormente incumplida, crea importantes frustraciones entre la opinión pública que, tras comprobar la imposibilidad de llevar a la práctica esa contención de fronteras, tiende a mostrarse partidaria de las propuestas de cierre más extremas.

b) Un coste económico, porque el mantener las fronteras cerradas supone un elevado gasto (en efectivos policiales o centros de retención) obteniendo resultados aleatorios que a veces son dificiles de compatibilizar con otras realidades económicas 37 .

c) A estos dos costes se une un tercero, el social, desde una doble perspectiva. Para el inmigrante, que con el cierre progresivo de las fronteras ve comprometidos aspectos tan importantes como el de la integración, puesto que, indirectamente se recortan derechos que contribuirian a la misma, tales como la reagrupación familiar. Por otra parte, también para la ciudadanía existe un elevado coste puesto que se la toma como estandarte para defenderse de la intromisión del otro, cerrando los cauces para el acceso a la nacionalidad, y haciendo de ésta una categoría exclusiva y excluyente que impide a los inmigrantes el pleno disfrute de derechos fundamentales en condiciones de igualdad ${ }^{38}$.

Además el creciente papel de la opinión pública, a menudo asediada por noticias relativas a la inmigración, pocas veces neutras, y por las opiniones partidistas con fines electorales, hace que ésta se convierta en un "control del control" (Wihtol de Wenden 2000, 18). Asi los Estados escenifican un control que en buena medida acaba siendo simbólico, por imposibilidad material, y muestran una firmeza que cede ante las regularizaciones extraordinarias, las cuotas anunciadas y no cumplidas, o las admisiones selectivas de trabajadores cualificados.

\subsection{Seguridad y Orden público}

Desde la perspectiva defensiva otros dos argumentos son básicos para entender la pretendida política migratoria de la Unión:

a) El discurso de la seguridad, que nos remite a la conexión entre inmigración y terrorismo como consecuencia del temor generado hacia cierto tipo de extranjero visto como potencial terrorista.

b) La lógica del orden público, que interrelaciona la inmigración con la criminalidad al asociarla, por una parte, a las

ARBOR CLXXXI 713 MAYO-JUNIO [2005] 81-100 ISSN: 0210-1963 
mafias de tráfico de personas y, por otra, a los delitos cometidos por los inmigrantes en los países de acogida.

En efecto, los acontecimientos del 11 de septiembre de 2001 tuvieron en lo que a la política migratoria de la Unión Europea se refiere consecuencias sumamente negativas. Tras el costoso consenso que se habia alcanzado en la Unión respecto a la necesidad de una política de aceptación, incluso paulatina promoción, de la inmigración se pasó a otra basada en la seguridad, con mayor vigilancia e información y menor libertad (Izquierdo 2003, 14). Todo ello supuso el consiguiente abandono de criterios considerados básicos en la dimensión internacional y la primacía del mencionado discurso de la seguridad entendido desde un modelo policial que contamina con su lógica de orden público todos los objetivos de la política de inmigración (De Lucas 2003 a, 24-25).

A pesar de la advertencia hecha por la Comisión, en relación a la necesidad de evitar que los efectos negativos del 11-S repercutieran sobre los inmigrantes, o en su caso sobre los refugiados o demandantes de asilo, lo cierto es que en la práctica esta salvaguarda no siempre se ha conseguido ${ }^{39}$.

Desde el Consejo de Laeken de $2001^{40}$, en el que se incitaba a una mejor gestión del control de las fronteras exteriores de la Unión para contribuir a la lucha contra el terrorismo, las redes de inmigración clandestina y la trata de seres humanos; hasta el Consejo de Bruselas de $2004^{41}$, en el que se adoptó la Declaración sobre la lucha contra el terrorismo, como consecuencia de los atentados del 11-M en España, no se ha dejado de insistir en el terrorismo como una cuestión vital a tener en cuenta e íntimamente conectada a la inmigración 42 .

A partir del punto de inflexión marcado por estos acontecimiento ya históricos, cuestiones como la eficacia en el control policial de los flujos, la lucha contra la inmigración ilegal o la política común de repatriaciones, se han convertido en un eje fundamental de la política europea. Esa obsesión sobre la seguridad ha provocado, y justificado, en distintos paises de la Unión reformas en sus legislaciones de extranjería e inmigración que, como señala de Lucas $(2003$ a, 28) amenazan con favorecer la falacia de identidad entre flujos migratorios y riesgo terrorista, especialmente si se trata de inmigrantes procedentes de paises árabes o islámicos. Se justifica así la restricción o la flagrante vulneración de derechos fundamentales de los inmigrantes en aras de un bien común. Ciertamente como mantiene Ignatieff $(2005,6)$ ante las emergencias terroristas se rompe la relación según la cual no es posible que haya democracia sin derechos $y$, al mismo tiempo, éstos no pueden estar garantizados sin aquella. En dichas emergencias lo que hace que la seguridad parezca triunfar sobre la libertad (podriamos decir también sobre otro tipo de derechos) es la idea de que la libertad de la mayoria depende por completo de su seguridad. En esta situación, si se entiende que los derechos son las conveniencias políticas que las mayorias establecen para su propia defensa, éstas tienen la potestad de recortarlos cuando la situación de necesidad lo requiera. Así parece interpretarse de modo más evidente en la política seguida por la administración norteamericana pero también, de forma más encubierta, en al articulada desde la Unión con respecto a la inmigración. Desde la defensa de la democracia basada en los derechos, podría argumentarse que éstos pierden su significado, tanto para los individuos que están en peligro cuanto para la mayoría si son revocables en situaciones de necesidad 44 .

Hasta tal punto ha adquirido una especial relevancia la clave de seguridad y orden público en el ámbito comunitario que el Tratado Constitucional de la Unión Europea contempla la denominada cláusula de solidaridad contra el terrorismo (artículo 43) ${ }^{45}$. La aplicación de dicha cláusula se concreta en el artículo 329 que, en opinión de algunos, permite realizar una interpretación extensiva (más allá del terrorismo, las catástrofes de carácter natural o humano) de las amenazas a las que se refiere el artículo 43 incluyendo, por ejemplo, los flujos migratorios. Así podría entenderse que la obligación de actuación solidaria por parte de los distintos Estados de la Unión alcanza a la presión migratoria en sus fronteras. Aunque desde determinados ámbitos se proponga esta interpretación extensiva, desde otros también se ha señalado el carácter impropio de esta analogia y su efecto estigmatizador, advirtiendo de las consecuencias perversas de la misma al reconducir el concepto de seguridad humana al de seguridad nacional, territorial o estatal, en un contexto distinto como es el de la Unión donde propiamente deberiamos referirnos al terrorismo internacional (Ramón 2005, 62-63).

Esta estrecha vinculación entre seguridad, terrorismo e inmigración presente en la política de la Unión, se completa, como advertía anteriormente, con otra muy semejante que asocia orden público, criminalidad y flujos migratorios. La amenaza al orden público que la inmigración implica se percibe desde dos perspectivas:

1 Desde el punto de vista de la lucha contra la inmigración ilegal, traducida en formas de combatir el tráfico

ARBOR CLXXXI 713 MAYO-JUNIO [2005] 81-100 ISSN: 0210-1963 
y la trata de seres humanos 46 , es decir, en medidas para combatir la actuación de las mafias que encuentran en la precaria situación de los inmigrantes, impotentes ante las múltiples trabas para su entrada legal en países de la Unión, el caldo de cultivo idóneo para sus actividades. Puesto que en la mayoría de casos estos hechos son constitutivos de delitos deberian perseguirse desde la perspectiva del derecho penal. Sin embargo, en la práctica buena parte de las legislaciones de extranjeria e inmigración de los paises europeos contemplan supuestos relativos a la inmigración clandestina en los cuales al confundir la actuación de la red organizada con la actividad del inmigrante clandestino (victima de la misma) es difícil delimitar, con claridad, la pertinencia de la sanción penal o la administrativa ${ }^{47}$.

2 Desde la consideración de todo inmigrante como potencial delincuente. Este argumento justifica el papel represivo de la legislación con medidas, en los distintos ordenamientos de los países de la Unión, que obligan al inmigrante a presentar sus antecedentes penales en cada trámite relativo a su residencia legal, a realizar personalmente determinadas gestiones, a someterse a continuos controles relativos al cambio de domicilio, nacionalidad o estado civil, a verificar sus medios de vida, las condiciones de su vivienda, etc.

La criminalización y etnización de determinadas actividades ilegales, junto con el recurso a las acciones represivas y penales y la hostilidad cada vez mayor respecto a la inmigración ${ }^{48}$, amenazan con acabar produciendo en Europa una categoria de la criminalidad inmigrante y de origen extranjero (Palidda 1999, 36). Si bien existen múltiples factores que deberíamos tener en cuenta para explicar esta aproximación entre inmigración y criminalidad, y su consiguiente reflejo en medidas represivas de los flujos en las legislaciones de los Estados europeos, hay un elemento, que algunos consideran básico, para justificar este discurso de orden público: si los extranjeros en el mercado de trabajo tienden a instalarse en los puestos inferiores, es decir, están predispuestos a ocupar la base de la pirámide legítima de la sociedad autóctona (trabajos peor remunerados, viviendas en inferiores condiciones, dificultades en el acceso a la sanidad y a la educación, formación precaria o inexistente, etc.), podria afirmarse que del mismo modo comienza también un proceso de reemplazo de los autóctonos por los inmigrantes en la base de la pirámide penal, en el ámbito de las actividades desviadas, especialmente en la delincuencia urbana (Palidda 1999, 38).
Aunque pudiera ser cierto que algunos extranjeros están especializados en determinados delitos, como se ha contrastado a través de informes 49 , sustituyendo o complementando en esta campo a los autóctonos, ello no significa que todos los extranjeros en cuanto a inmigrantes lo estén. Incurrir en esta reducción nos llevaría a la misma estigmatización, que señalábamos anteriormente, que reconduce a todos los inmigrantes a la categoría de potenciales terroristas.

Esta generalización, aún siendo inaceptable por los efectos perversos que puede producir, se encuentra en la base de la política migratoria de la Unión en la que tiende a obviarse que con relación a los inmigrantes irregulares una parte importante de los delitos que se les atribuye son udelitos de subsistencian, es decir, directamente vinculados con su situación de total precariedad (Wihtol de Wenden 2000, 69).

\section{Clave social}

Un tercer aspecto relevante en la configuración de la política comunitaria de inmigración, es el sustrato social aparentemente homogéneo, aunque sería mejor decir homogeneizador, que se toma como referencia. Esta política desde la perspectiva social viene marcada por el intento de proteger a los europeos frente a la invasión o a la posible desnaturalización consecuencia de la inmigración. Así se considera que existe una homogeneidad cultural y social que en realidad ni siquiera puede encontrarse, en muchos casos, a nivel nacional.

Aunque se pretenda insistir en la identidad europea como una "identidad de identidades» plural e inclusiva, el proyecto homogeneizador en todos sus aspectos, económico, politico y también cultural, sigue estando presente ${ }^{50}$. Como mantiene De Lucas (2003 b, 98-99 y 2005, 30-31) Europa existe puesto que tiene un territorio, una historia y una herencia, pero eso no significa que ese depósito nos permita hablar de identidad común. Más bien en lo que respecta a la Unión parece que la política y el Derecho, aunque sea como resultado de la concepción de mercado, preceden a la historia y la cultura.

\subsection{La pretendida homogeneidad europea}

Como para articular politicas comunes parece imprescindible creer, o hacer creer, firmemente en la existencia de esa homogeneidad, el debate sobre el fundamento, el sentido 
o el alcance de la reiterada identidad europea parece obviarse. Se toma como referencia la Unión de los europeos y se crea una categoría aglutinadora denominada ciudadanía europea, intimamente ligada a la pertenencia a un Estado de la Unión. Las exclusiones que se generan a partir de este punto son tan automáticas como las que se han producido tradicionalmente en el seno del Estado-nación ${ }^{51}$.

El artículo 10 del Tratado Constitucional de la Unión Europea vincula la ciudadanía europea a la posesión de la nacionalidad de algunos de los Estados miembros y, a partir de ahi, el disfrute de derechos. Por ejemplo, sólo los ciudadanos europeos tendrán derecho a la libertad de circulación. Sin embargo, entre ellos también se sigue criterios de nacionalidad diferenciadores. Para los ciudadanos de los antiguos Estados miembros no existen limitaciones. En cambio, los que pertenezcan a los nuevos Estados adheridos a la Unión, pueden tener este derecho restringido por algunos años. Para los extracomunitarios la libertad de circulación no se configura como un derecho sino más bien como una concesión a los residentes legales en el territorio de un Estado miembro (artículo 105, punto 2).

Por lo que se refiere a los ciudadanos de la Unión, en virtud del acuerdo de transición entre la Europa de los Quince y la Comisión Europea, paises como Estonia, Letonia, Lituania, Hungria, Polonia, República Checa, Chipre, Malta, Eslovenia y Eslovaquia, aunque sean oficialmente miembros de la Unión, tienen limitado, además de la libertad de circulación, el acceso al mercado de trabajo y al sistema de bienestar, de acuerdo con lo que establezcan las políticas estatales y los acuerdos bilaterales entre los antiguos y los nuevos miembros de la Unión. Estas limitaciones se aplicarán sólo por un periodo transitorio atendiendo a los siguientes criterios (Tornos 2004, 244-245):

1 Tras las adhesión, durante los primeros años las antiguos miembros de la Unión pueden exigirles a los trabajadores de los nuevos Estados miembros los mismos permisos que hasta ese momento les estaban exigiendo. Estas medidas afectan al trabajo por cuenta ajena, pero no a aquellos que deseen instalarse como autónomos, rentitas, estudiantes o familiares de los ya residentes.

2 En la aplicación de estas medidas se distinguen:

a) Un primera fase de dos años: en la que se mantendrán las mismas restricciones hasta ahora aplicadas a la inmigración de trabajadores.

b) Una segunda fase de tres años: en la que los antiguos
Estados elegirán si mantienen la exigencia de permisos de trabajo o liberalizan la circulación de trabajadores.

c) Una tercera fase de dos años: en la que los mismos países aún podrán restringir la libertad de circulación si acreditan, ante los organismos de la Unión, que existen amenazas graves para el mercado de trabajo.

Transcurrido este período ya no se le podrá exigir un permiso o autorización de trabajo a ningún ciudadano de un nuevo Estado miembro.

La construcción de Europa, por tanto, además de ir unidad a la pertenencia a los paises miembros, tiene en cuenta las exigencias e intereses de cada uno de los Estados, por ejemplo, en caso concretos como Alemania y Austria que exigieron las mencionadas restricciones como forma de proteger la apertura de sus fronteras hacia el Este ${ }^{52}$. Esa forma de pensamiento estatalista que se traslada a la Unión se refleja claramente en el Tratado Constitucional que, en opinión de algunos (Braidotti 2003, 70-71) representa una regresión respecto a los textos fundadores de la Unión en el período posterior a la Segunda Guerra Mundial, precisamente por esa sumisión a la voluntad de los paises.

La lógica comunitaria respecto a los flujos migratorios, la voluntad aglutinadora de defensa frente al exterior, no es más que el reflejo de la lógica estatal. Ambas comparten la misma representación y definición del inmigrante y de la inmigración (Gil Araújo 2005, 49) e idéntica primacia economicista.

A pesar de las notables diferencias internas entre los propios Estados miembros de la Unión, en la articulación de una politica de inmigración europea se insiste en mantener la unidad interna para sustentar lo que Balibar (1999, 108-109) ha denominado el "apartheid europeo" 53 . Este término hace referencia a una pretendida identidad común, homogeneizadora, frente a la cual términos como inmigrantes, clandestinos, irregulares, extracomunitarios, se aúnan en uno solo: los no europeos. Para "los otros» muchos de sus derechos y libertades ya no irán unidos a la condición de persona, sino a la de trabajador, puesto que esta situación es la que facilita la residencia legal y de ahí el disfrute de algunos beneficios legales. Todo ello combinado con la dinámica nacional de medidas parciales de integración para la inmigración legal y la insistencia comunitaria de que la integración debe ser un principio fundamental irrenunciable en 
las políticas estatales. Un círculo de contradicciones que en el fondo contribuye al desarrollo de ese apartheid.

\subsection{La integración «de» los inmigrantes}

Desde que la COM (2000) 757 configurara la integración como «un proceso bidireccional basado en derechos mutuos y obligaciones correspondientes a los ciudadanos de terceros paises en situación legal y de la sociedad de acogida, que permite la plena participación de los inmigrantes», las Comunicaciones posteriores, al menos en su formulación teórica, no se han apartado de esta consideración bipolar. Sin embargo, en la práctica la mayoría de medidas en los distintos Estados de la Unión tendentes a la consecución de la integración se han articulado concibiéndola como un proceso unilateral en el que es el inmigrante el que debe integrarse en la sociedad de acogida.

En realidad, las directrices europeas distan de las políticas estatales al señalar que la integración debe concebirse desde una perspectiva multidimensional $u$ holistica en la que intervienen distintos elementos y agentes (COM 2003, 336) ${ }^{54}$ :

1 Elementos: aunque al abordar la cuestión de la integración no se renuncia a la clave económica dominante en relación a los flujos migratorios, es decir, a la concepción utilitarista o instrumental de la inmigración (De Lucas 2003 b, 49), se insiste en la necesidad de facilitar el acceso a los derechos sociales: educación (y conocimientos lingüisticos), vivienda (y problemas urbanos), sanidad y servicios sociales.

La participación política de los extranjeros inmigrantes aparece como tercer aspecto decisivo de las políticas de integración. Sin entrar en el arduo debate de la relación entre ciudadanía y nacionalidad 55 , a la que ya me he referido anteriormente, es necesario dejar constancia de la estrecha conexión que desde la Unión Europea se ha mantenido entre ciudadanía civica (como forma de participación) e integración ${ }^{56}$.

Con la evidencia de que los paises que han optado por conceder el voto a los residentes extranjeros, comenzando por las elecciones municipales, no han sufrido ninguna desestabilización en la politica local ${ }^{57}$, sino que han permitido que emergieran élites ciudadanas incluso, como señala Wihtol de Wenden $(2003,257)$, en un cantidad más significativa que en el modelo meritocrático, no parece que las criti- cas al mismo puedan seguir manteniéndose. Más bien al contrario, como sostiene la COM (2003) 336 «desde el punto de vista de la integración, es obvio que el derecho de voto local no debería derivarse de la nacionalidad sino de la residencia permanente» 58 .

2 Agentes: aunque corresponde a los Estados asumir la iniciativa en la puesta en marcha de una política de integración multidimensional, la condición fundamental para aplicar de modo adecuado este planteamiento es, por una parte, mejorar la coherencia entre las políticas de inmigración, integración y empleo a todos los niveles y en el conjunto de las disciplinas; $y$, por otra parte, incluir a los interlocutores sociales, al sector de la investigación, a los proveedores de servicios públicos, a las ONGs y otros agentes de la sociedad civil, entre quienes necesariamente se encuentran los inmigrantes ${ }^{59}$. La puesta en marcha de este tipo de politica exige actuaciones en un doble nivel:

a) En los paises de origen, cuya colaboración resulta vital en la definición de la situación en la que se encontraran sus nacionales que residan en otro Estado.

b) En los paises de acogida, potenciando la acción de la sociedad civil en la integración de los inmigrantes.

Los interlocutores sociales, en general a nivel nacional pero de modo muy significativo en el ámbito local, desempeñan un papel fundamental en la representación de los inmigrantes, que garantiza la cooperación y comprensión entre los proveedores de servicios y sus usuarios. Estos agentes deben asumir un papel relevante en la integración cotidiana de los inmigrantes, potenciando el diálogo para definir y llevar a la práctica las políticas, pero no son los únicos implicados 60 .

Los propios inmigrantes constituyen otro de los agentes. Aunque pueda resultar una obviedad el mantener que los inmigrantes deben participar en la integración del colectivo al que pertenecen, parece que la práctica demuestra que no es así, sobre todo si se tiene en cuenta que dicha participación exige una concreción político-jurídica en forma de derechos, en una línea semejante a la política de la presencia propuesta por Phillips (1995 y 1999, 235-256).

Aunque estas son la propuestas que la Comisión ha ido realizando a través de sus comunicaciones, lo cierto es que 
el primer informe anual sobre migración e integración 61 ofrece un panorama que dista mucho del modelo teórico. Como el propio informe reconoce al analizar las tendencias en las políticas nacionales de integración, la mayor barrera para la misma es la imposibilidad de acceder al empleo. Dicha dificultad debería constituir la prioridad de las políticas nacionales de integración, lo cual, como se evidencia en los anexos relativos a distintos países no está ocurriendo.

En realidad, lo que el informe señala como progresos hacia una política de inmigración común, desde su perspectiva juridica, se reduce a Directivas ${ }^{62}$ que contemplan un Derecho de mínimos para no obligar a los Estados a realizar importantes modificaciones en sus legislaciones internas a la hora de realizar la transposición. Aunque se constatan las dificultades de los extranjeros por motivo de nacionalidad a la hora de acceder al empleo, manifestando así las evidentes condiciones de desigualdad en la que éstos se encuentran en el reconocimiento y disfrute de sus derechos, no se propone ninguna alternativa, propuesta o sugerencia de actuación para los paises miembros.

La integración es, por tanto, una especie de uprincipio expectante» en su aplicación práctica, sistemáticamente reiterado, con pocas medidas estatales o europeas para llevarlo definitivamente a la práctica. Ante la evidente falta de consenso para articular medidas comunitarias de integración de los inmigrantes, puesto que como constata el informe sólo existen algunos puntos nacionales de contacto, parece que la tendencia general en el futuro de la normativas comunitarias en materia de integración será la armonización a la baja (Gil Araújo 2001 y 2005, 47), tal como ha ocurrido hasta ahora 63 , puesto que la estrategia de empleo, la clave económica a la que antes aludía, sigue siendo prioritaria.

En este sentido resulta sumamente significativa la previsión que contempla el Tratado Constitucional de la Unión Europea al referirse en su capítulo IV a la ya mencionada ley o ley marco europea que se ocupará de cuestiones relacionadas con la inmigración. En lo relativo a la integración el artículo 267, en su punto 4, mantiene que dicha ley podrá establecer medidas encaminadas a fomentar y apoyar la acción de los paises miembros destinadas a favorecer la integración de los nacionales de terceros países residentes legales "con exclusión de toda armonización de las disposiciones legales y reglamentarias de los estados miembros".

\section{Recapitulación: cuestiones para el debate}

De lo expuesto hasta aqui podemos sintetizar algunos aspectos de especial relevancia en la política de inmigración de la Unión que muestran sus flagrantes contradicciones internas y cuyo enfoque no es, ni mucho menos, una cuestión cerrada:

A Desde la perspectiva económica, la Unión apuesta por la defensa del mercado comunitario priorizando la ocupación laboral de los ciudadanos de la Unión y, en su caso, de los ya residentes, condicionando las nuevas entradas a la existencia de vacantes formales y $\sin$ atajar los mecanismos que hacen que proliferen los nuevos esclavos.

En general, el trabajo legal no es atractivo para los inmigrantes por la escasa demanda de mano de obra poco cualificada. Es decir, por la falta de adecuación entre las cuotas y la demanda laboral real. En su lugar el mercado ilegal es el principal factor de atracción de los extranjeros extracomunitarios, coincidiendo en muchas ocasiones los sectores (agricultura, hostelería, construcción o servicios), de uno y otro ámbito, pero no las condiciones.

De esta forma la economía sumergida y la inmigración se retroalimentan. Los Estados al mismo tiempo que mantienen una política formal de inmigración restrictiva, intentan a través de instrumentos como los contingentes o los contratos de temporada responder a las necesidades laborales, consintiendo el trabajo clandestino.

B En cuanto al discurso defensivo, los distintos paises de la Unión limitan la inmigración extracomunitaria por distintos temores de seguridad y orden público, siendo la experiencia de un pais en el control de la inmigración considerada como fundamental para su eficiencia. A pesar de ello, los esfuerzos por controlar las entradas, como los destinados a proteger el mercado de trabajo, han sido en gran medida infructuosos y han obligado a los distintos paises a acudir a amnistías generales. Tampoco las formas de control de la inmigración en los paises de origen, que deberia reducir los incentivos para emigrar, han conseguido los resultados esperados.

Todo ello combinado con una fuerte politización del control de la inmigración. Asi diversos partidos, en distintos Estados, han incluido en sus campañas propuestas para

ARBOR CLXXXI 713 MAYO-JUNIO [2005] 81-100 ISSN: 0210-1963 
frenar la inmigración con medidas tendentes al proteccionismo y favorecedoras del nacionalismo.

La dinámica de la seguridad ha impuesto una mayor selección de los admitidos en los Estado de la Unión, haciendo ceder derechos que parecian consagrados y poniendo en tela de juicio algunos de los pilares de nuestras democracias.

C. En el ámbito social la miopía esgrimida en aras del discurso homogeneizador ha pretendido soslayar las cuestiones identitarias, incidiendo en otras como la ciudadanía europea que trasladan al ámbito comunitario la dualización y exclusión propia de una categoria heredada del más estricto discurso del Estado-nación, que perjudica la integración de los inmigrantes extracomunitarios.

La parquedad a la hora de proponer medidas integradoras y la nula voluntad europea de incidir en las decisiones estatales que sobre esta cuestión se adopten, deja al libre albedrío de los respectivos gobiernos una de las cuestiones fundamentales en la gestión de la inmigración. La aparente concepción graciable de elementos imprescindibles para conseguir la integración la acerca más a una recompensa por la capacidad del extranjero de adaptarse a las imposiciones estatales, que al proceso bidireccional que la Unión mantiene que debería ser. Hasta ahora, siguen habiendo Estados, como el español, que se niegan a concebir la integración en forma de derechos y continúan limitando el pleno disfrute de los derechos sociales o vetando el acceso a los políticos, incluso en su expresión más básica, como si aquella fuera posible sin éstos.

Por tanto, teniendo presente que, para no exacerbar las voluntades estatales, la paulatina armonización de las politicas nacionales de inmigración y la construcción de una comunitaria se propone a la baja y, en todo caso, en el marco de una "convergencia condicionada" (Brochmann 1999, 334), no está de más recordar la necesidad de hacer frente a las mencionadas paradojas desde otra voluntad que no sea la mera creación del ejercito industrial de reserva del que hablaba Marx. Asi pues, un largo, y nada fácil, camino le queda por recorrer a esa pretendida ley marco europea si quiere dotar de coherencia, sentido y sobre todo eficiencia y eficacia, la política de inmigración europea. 
1 Sobre terrorismo, radicalismo, extremismo y violencia internacional, creado el 1 de noviembre de 1975, a iniciativa de los $\mathrm{Pa}$ ises Bajos, en la reunión en Roma de los jefes de gobierno de la Comunidad Económica Europea.

2 Vid. Ahijado (2000) y Carpentier y Lebrun (2004).

3 Como señala Brochmann (1999, 310-311) el acuerdo de Schengen fue la base para la politica de inmigración europea, ya que, todos los paises participantes en él deseaban reducir la tasa de inmigración ilegal, punto básico en dicha política. Cfr. Del VaIle ( 2004, 67-92).

4 Vid. Blade (2003) y Tandonnet (2001, 149-160).

5 Cfr. Martín y Pérez de Nanclares (2002 y 2003, 93-118).

6 Vid. Olesti (2000) y Carpentier y Lebrun (2004).

7 Desde la Comunicación de la Comisión al Consejo y el Parlamento Europeo relativa a un método abierto de coordinación de la política comunitaria en materia de inmigración, COM (2001) 387 final.

8 Los Estados se niegan a renunciar a su soberanía en esta materia, con las consiguientes implicaciones Cfr. Balibar (2003, 19-30). Aunque se pretende aunar voluntades la filosofía de los distintos Estados en materia migratoria no siempre es coincidente. Según Tandonnet (2001, 160171), sin contar las últimas incorporaciones, podriamos clasificar las distintas concepciones de los Estados de la Unión en: 1) los "continentales", como Alemania, Austria, los Paises Bajos o Bélgica, con un número importante de demandantes de asilo que apuestan por una política de solidaridad europea en materia de asilo e inmigración (como veremos más adelante a propósito del Tratado Constitucional de la Unión Europea); 2) los «atlánticos», como Francia, Reino Unido e Irlanda, fuertemente influidos por su historia colonial; 3) los "generosos" entre ellos los paises escandinavos, con una tradición de respeto al derecho de asilo y de puesta en marcha de mecanismos de integración; 4) los «positivos", como Italia, Grecia, España y Portugal, que se encuentran entre los nuevos paises de inmigración.
9 Obviamente ésta no es al única forma de entrar en un Estado de la Unión, además de la inmigración laboral existen, al menos, otras tres upuertas de entrada»: la reagrupación familiar, el asilo (cada vez más limitado) y la inmigración irregular (Tandonnet 2001, 23-49).

10 Como señala Sassen $(2001,95)$, la politica migratoria, en los paises más desarrollados, está reñida con otras estructuras de primer orden en el sistema internacional. Asi mientras se pretenden blindar las fronteras para impedir la entrada de inmigrantes y refugiados, se propende crear espacios económicos sin fronteras. Parece que por una parte discurren los flujos de capital y de información, y por otra los movimientos de personas, la inmigración.

11 Sobre lo efectos de la inmigración en el mercado de trabajo de la sociedad receptora como breve resumen vid., por ejemplo, Bosniak $(1992,737-770)$ y Noya $(2003$, 45-55). Para un perspectiva comparada Rotte and Stein (2002).

12 Cfr. Trinidad García (2002, 493-505).

13 Definida, de momento, desde esta perspectiva: «Los Estados miembros sólo tendrán en cuenta las solicitudes de entrada en sus territorios por razones laborales cuando los puestos vacantes en el estado miembro de que se trate no puedan ser ocupados por los trabajadores nacionales o comunitarios, ni por los trabajadores no comunitarios que residan legalmente y de forma permanente en dicho estado miembro y que formen parte del mercado laboral del mismon (Resolución del Consejo, de 20 de junio de 1994, en relación con el reglamento (CEE) no 1612/1968 del Consejo). En el mismo sentido, el Tratado de Adhesión de 16 de abril de 2003 concede preferencia a los trabajadores nacionales de los Estados miembros sobre los nacionales de terceros paises en el acceso al mercado laboral de los Estados miembros.
14 Si como señala Laporta (2001, 67-68), a propósito del mencionado libro de Sartori con el que afirma coincidir en el planteamiento general aunque no del todo en las premisas y las conclusiones, la ética en la que se basan las sociedades abiertas (como entiendo que pretende ser la nuestra) "consiste en adscribir a cada uno de los individuos que las integran un conjunto de derechos fundamentales y establecer como regla básica del juego que tales derechos son inviolables... Siempre que la sociedad confiere esos derechos está atribuyendo a su titular lo que en el lenguaje moral se llama dignidad humanan. Entonces no puede mantenerse, en mi opinión, que un buen número de individuos (extranjeros inmigrantes) que de hecho integran esa sociedad jamás (según el planteamiento de Sartori) podrán acceder a determinados derechos fundamentales, porque ese planteamiento significaria romper la regla básica de juego y como consecuencia negar la dignidad humana de esos individuos, ¿acaso esa negación es aceptable en el marco social y democrático de nuestro Estado de Derecho?. 
15 Así lo señala Noya $(2003,56-57)$, siguiendo la teoría económica de los bienes de club de Breuer, al referirse al Estado de Bienestar como "un ramillete de bienes de clubin. Además recuerda que según las modelizaciones económicas sobre el impacto de las migraciones en las prestaciones sociales, puede destacarse el modelo Epstein/Hillman, en base al cual: a) la inmigración aumenta el ejercito de reserva y desplaza a los trabajadores nativos hacia actividades con salarios más bajos, con lo cual la inmigración supone un instrumento de disciplinamiento para el capitalista; b) si las prestaciones sociales de los inmigrantes son demasiados bajas, éstos desplazarán a los trabajadores nativos del mercado de trabajo, de forma que los autóctonos no se beneficiarán de la inmigración; c) si existe un número mayor de inmigrantes, bajan los salarios y aumenta el empleo, pero para cualquier nivel de beneficios sociales, existe un umbral superior en el número de inmigrantes que disciplina a los trabajadores nativos y ese umbral desciende con el número de inmigrantes. A partir de ahi, como concluye el mencionado autor pueden derivarse consecuencias sobre las preferencias de los diferentes actores respecto a la protección social de los inmigrantes.

16 Vid. Comité de Política Económica, AAspectos económicos de la inmigración" EC$\mathrm{FIN} / 361 / 03$.

17 Acontecimientos como los de El Ejido son una muestra de la práctica de una politica represiva estricta para los inmigrantes y débil para los autóctonos, Vid. Goytisolo y Naïr (2000, 181-186 y 207-226)

18 En agosto de 2001, después de que el barco de bandera noruega, el Tampa, rescatara a más de 400 hombres, mujeres y niños de una embarcación indonesia que se estaba hundiendo cerca de las costas de Australia, las autoridades australianas no permitieron desembarcar a las personas, temiendo que pidieran asilo.

19 Para un análisis comparado de los procesos de regularización en distintos Estados de la Unión vid. De Bruycker (2000).

20 Cfr. Carrasco (1999).
21 La inexplicable ausencia de suficientes inspecciones de trabajo que acaben con la explotación de los inmigrantes irregulares alimenta el que los empresarios se animen a aprovecharse de ellos. Es como si existiera una indulgencia global de la Administración y la justicia de la que se benefician los empresarios transgrediendo sin problemas las disposiciones del derecho laboral relativas a la protección de los trabajadores (Terray 1999, 25). No puede olvidarse que también cuando los empresarios desean emplear a extranjeros en situación regular o colaborar en la regularización de inmigrantes ofreciéndoles la oferta de empleo que éstos necesitan existen tantas trabas burocráticas que la contratación legal acaba llegando demasiado tarde.

22 Sobre la situación de los extranjeros en situación irregular en distintos Estados de la Unión vid. Gibney (2000) y Wihtol de Wenden and Mohsen-Finan (2001).

23 Asi lo expone Terray (1999, 28-29) en un ejemplo que, desgraciadamente se repite a diario: si se descubre una obra o un taller clandestinos las verdaderas víctimas serán los inmigrantes en situación irregular que serán inmediatamente retenidos para ser reconducidos a la frontera. En cambio el intermediario será, como mucho, sancionado con una multa cuya cantidad puede fácilmente amortizarse en pocas semanas con el funcionamiento de una nueva obra o taller clandestino. Además, los grandes talleres y obras que funcionan en la clandestinidad estarán "au-dessus de la mêlée» manteniendo el principio de determinación de la sanción inversamente proporcional a la gravedad de la infracción que parece regir en la legislación de extranjería, al menos, en lo que al inmigrante se refiere.

24 Sobre los mecanismo de control puestos en marcha en Alemania, Francia, Austria, Holanda, Suecia, Noruega, Hungría e Italia, vid Brochmann and Hammar (1999)

25 Vid. Roldán Barbero $(2000,237-270)$ y Martín y Pérez de Nanclares $(2003,93-$ 118).

26 Cfr. Hayter (2000).
27 Plan para la gestión de las fronteras exteriores de los Estados miembros de la Unión Europea, adoptado por el Consejo de Ministros JAl, el 13 de junio de 2002, Doc. del Consejo 10019/02, FRONT 58. Cfr. Comunicación de la Comisión al Consejo y Parlamento Europeo, "Hacia una gestión integrada de las fronteras exteriores de los Estados miembros de la Unión Europea", COM (2002) 233 final.

28 Se fomenta también la asistencia mutua, entre los Estados miembros, en materia de repatriación o alejamiento con la finalidad de conseguir el objetivo común de poner fin a la estancia ilegal de nacionales de terceros paises que deban abandonar el territorio, a través de la Directiva 2003/100/CE del Consejo de 25 de noviembre de 2003 sobre la asistencia en casos de tránsito a efectos de repatriación o alejamiento por vía aérea, DO L 321 de 6 de diciembre de 2003.

29 Reglamento (CE) n 377/2004 del Consejo de 19 de febrero de 2004 sobre la creación de una red de funcionarios de enlace de inmigración, DO L 64 de 2 de marzo de 2004.

30 Vid. Commission Staff Working Paper, Annual report on the development of a common policy on illegal immigration, smuggling and trafficking of humans beigns, external borders, and the return of illegal residents, Commission of the European Communities, 25 de octubre de 2004.

31 Vid. Solanes y Cardona $(2005,134-141)$ y Martinez Martínez (2001, 277-300).

32 Directiva 2001/51/CE del Consejo, de 28 de junio de 2001, por la que se completan las disposiciones del artículo 26 del Convenio de aplicación del Acuerdo de Schengen de 14 de junio de 1985. Vid. DO L 187 de 10 de julio de 2001.

33 Además, con posterioridad, la Comunicación relativa a una política común de inmigración señalaba que, tras la mencionada Directiva, era necesario un reflejo en futuros reglamentos con la intención de conseguir una mayor armonización en lo relativo a la responsabilidad del transportista favoreciendo una discusión pormenorizada entre todas las partes interesadas. Comunicación de la Comisión al Consejo y al Parlamento Europeo final relativa a una politica común de inmigración ilegal, COM (2001) 672 final, de 15 de noviembre de 2001, en concreto, en el apartado 4.7.5 relativo a la responsabilidad del transportista.

ARBOR CLXXXI 713 MAYO-JUNIO [2005] 81-100 ISSN: 0210-1963 
34 Las sanciones pecuniarias aplicables van de un máximo no inferior a 5.000 euros, o un importe máximo de la sanción aplicada a tanto alzado a cada infracción no inferior a 500.000 euros (con independencia del número de personas transportadas), a un minimo no inferior a 3.000 euros. Estas sanciones constituyen sólo un punto de referencia, ya que, la Directiva deja la posibilidad a cada uno de los Estados de concretar otras como la inmovilización, incautación y decomiso del medio de transporte, o la suspensión provisional o retirada de la autorización de explotación. Los transportistas tienen reconocidos los derechos de defensa y de recurso en función de los ordenamientos de cada uno de los Estados, lo que significa que la garantía y efectividad de los mismos quedan circunscritas a las legislaciones nacionales.

35 Directiva 2004/82/CE del Consejo, de 29 de abril de 2004, sobre la obligación de los transportistas de comunicar los datos de las personas transportadas, vid. DO L 261 de 6 de agosto de 2004. Conviene señalar que esta Directiva arranca de la iniciativa presentada por el Reino de España en abril de 2003 (Vid. DO C82 de 5 de abril de 2003) de forma que, teniendo en cuenta que a partir del 1 de Mayo de 2004 el Consejo ya no podia decidir por iniciativa de un Estado miembro, se optó por adoptarla sin Dictamen del Parlamento con la finalidad, como se señala en la misma, de "evitar un vacio en la acción de la Comunidad en la lucha contra la inmigración ilegaln.

36 Cfr. Cornelius, Martin and Hollifield (2003).

37 Como por ejemplo la realidad del turismo en España pues, como es sabido, durante mucho tiempo un número importante de inmigrantes han entrado en nuestro pais con visado de turista quedándose más tarde en situación irregular.

38 Se convierte asi la ciudadania en lo que De Lucas ha denominado una "jaula de hierro" para la integración de los inmigrantes (De Lucas 2004, 215-236).

39 Vid. COM (2001) 743 final, de 5 de diciembre de 2001. Cfr. Ignatieff (2004, 4-11).

40 Vid. Conclusiones de la Presidencia, Consejo Europeo de Laeken, 14 y 15 de diciembre de 2001.

41 Vid. Conclusiones de la Presidencia, Consejo Europeo de Bruselas, 25 y 26 de marzo de 2004.

42 Cfr. Walzer (2004, 10-20).
43 Sobre la representación cada vez más estrecha entre Islam y terrorismo en Europa. vid. Goody (2004) y AlSayyad y Castells (2003).

44 Cfr. Ferrajoli (1999 y 2001) y Zagrebelsky (1997).

45 Como señala Aldecoa esta cláusula nace ligada a los atentados del 11-M, que constituyen el caso más grave de atentado terrorista sufrido por un país de la Unión. Ante dichos acontecimientos se puso de manifiesto la solidaridad europea y en el inmediatamente posterior Consejo de Bruselas de 2004 se propuso adelantar la vigencia de la cláusula de solidaridad del Tratado Constitucional de la Unión Europea para no retrasar la puesta en marcha de medidas que asegurasen una respuesta eficaz ante ataques terroristas tan graves como los de Madrid. Vid. Aldecoa 2004 (a y b) y 2005 (4-15).

46 Protocolos Adicionales II y III a la Convención de Naciones Unidas contra la Delincuencia Organizada Transnacional, adoptada por la Asamblea General de las Naciones Unidas el 15 de noviembre de 2000 , mediante resolución $\mathrm{A} / \mathrm{RES} / 55 / 25$. En la conferencia celebrada en Palermo, el 12 al 15 de diciembre de 2000, el comisario europeo Antonio Vittorino, firmó en nombre de la Unión esta Convención así como sus protocolos adjuntos.

47 Para el caso español vid., entre otros, Garcia España y Rodriguez Candela (2002) y Laurenzo Copello (2002).

48 Esta hostilidad se pone de manifiesto incluso en el tratamiento juridico diferenciado que reciben los extranjeros en las cárceles, el caso de España es un buen ejemplo (Garcia España 2003, 43-64).

$49 \mathrm{Vid}$, por ejemplo, en relación a España, Italia y Francia, el informe de investigación: criminalidad e inmigración, en el que se señala que el fenómeno de la especialización étnica criminal es una caracteristica común en los tres casos nacionales (Omicron 2001, 6).

50 Balibar $(2003,53-60$ y $149-155)$ y Castells y Serra (2004).
51 No pretendo en este punto abordar la controvertida cuestión de la identidad europea ni tampoco la de la ciudadanía de la Unión, por una parte porque no siendo el objeto de mi análisis desbordaria las posibilidades de este trabajo $y$, por otra, porque existen interesantes aportaciones que ofrecen una indudable claridad a la cuestión vid, por ejemplo, Wihtol de Wenden (1999 a); Balibar (2003); Todorov (2003); De Lucas (2003 b y2004); Bauböck (2001 a, 2001 b y 2004), Zapata-Barrero (2004) y Zincone (2004), entre otros.

52 Cfr. Ahijado (2000) y Carpentier y Lebrun (2004). Al mismo tiempo se multiplican los esquemas migratorios de forma que es difícil captar las perspectivas migratorias en Europa vid. Martiniello (2003, 20-31).

53 El Tratado de Maastricht prevé la atribución de la ciudadania europea, y con ella el derecho al voto local en los paises de residencia y el de petición o recurso ante los tribunales europeos, sólo para los nacionales de los estados miembros. Los trece millones de nacionales de terceros paises instalados en suelo europeo, que son indispensables para el bienestar de Europa, se convierten en ciudadanos de segunda 0 residentes sometidos al servicio de los europeos de pleno derecho, aunque sean residentes de larga duración o permanentes (Balibar 2003, 88).

54 COM (2003) 336 final, de 3 de junio, Comunicación de la Comisión al Consejo, al Parlamento Europeo, al Comité Económico y Social Europeo y al Comité de la Regiones, sobre inmigración, integración y empleo.

55 Cfr. Dictamen del Consejo Económico y Social Europeo sobre el tema "Incorporación a la ciudadanía de la Unión Europea" SOC 141-CESE 593/2003.

56 Para interpretarla podriamos acudir a la puntualización que hace Bauböck a propósito de la cuestión sobre si la igualdad de derechos de ciudadanía implica o no igualdad de obligaciones. Según el mencionado autor la respuesta debe ser negativa, puesto que, "las desigualdades de derechos y las desigualdades de obligaciones necesitan ser justificadas independientemente, cada uno respecto a las capacidades especificas, recursos, necesidades y compromisos que están en juego en la distribución de bienes sociales particulares" (Bauböck 2004, 199). 
57 Entre ellos Dinamarca, Irlanda, Holanda, Suecia y Finlandia. En el caso de Bélgica, en febrero de 2004 se aprobó la ley que concede el derecho al voto a los extranjeros extracomunitarios en la elecciones municipales (sin que sean elegibles). Esta ley se aplicará a partir del próximo escrutinio municipal en 2006.

58 La Comisión considera, en la mencionada Comunicación (punto 3.3), que el Tratado podría constituir la base para conceder derechos políticos a los inmigrantes residentes de larga duración. Cfr. Directiva 2003/19/CE del Consejo, de 25 de noviembre de 2003, relativa al estatuto de los nacionales de terceros paises residentes de larga duración.

59 Así lo mantiene la COM (2003) 336, en su punto 3.4 , señalando que un mejor gobierno de las cuestiones relacionadas con la inmigración pasa por la cooperación más estrecha entre los diferentes agentes "desde las autoridades locales a las regionales, nacionales y comunitarias, incluyendo a los paises de origen".

60 Vid. Conferencia sobre «Inmigración: el papel de la sociedad civil en la promoción de la integración", Bruselas, 9 y 10 de septiembre de 2002.

61 COM (2004) 508 final, de 16 de julio de 2004, Primer informe anual sobre inmigración e integración, tal como se proponía en la COM (2003) 336 final.

$62 \mathrm{El}$ informe expresamente se refiere a la Directiva sobre el derecho a la reagrupación familiar (Directiva 2003/86/CE del Consejo de 22 de septiembre de 2003), la Directiva relativa a residentes de larga duración (Directiva 2003/109/CE del Consejo de 25 de noviembre de 2003) y la Directiva relativa a la expedición de un permiso de residencia a los nacionales de terceros paises que sean victimas de trata de seres humanos o hayan sido objeto de una acción de ayuda a la inmigración ilegal, que cooperen con las autoridades competentes (Directiva 2004/81/ CE del Consejo de 29 de abril de 2004).

63 Sobre modelos y politicas de integración en distintos Estados de la Unión vid. Wihtol de Wenden (1999 b,121-156).

\section{BIBLIOGRAFÍA}

Ahijado Quintillán, M. (2000): Historia de la unidad europea. Desde os precedentes remotos a la ampliación del Este, Madrid, Pirámide.

Alsayyad, N. y Castells, M. (eds.) (2003): ¿Europa musulmana o euro-islam?: política, cultura y ciudadanía en al era de la globalización, Madrid, Alianza.

Aldecoa Luzárraga, F. (2004 a): "La Conferencia Intergubernamental asume el proceso constituyente al hacer suya la Constitución para Europan, Documento de Trabajo del Real Instituto Elcano 94/2004, en www.realinstitutoelcano.org

Aldecoa Luzárraga, F. (2004 b): Constitución europea: una politica de paz, Madrid, Paz y Libertad.

Aldecoa Luzárraga, F. (2005): «El largo camino hacia la Constitución Europea. De la idea de Europa al Tratado por el que se establece una Constitución para Europa: una federación europea para al paz", Éxodo, n 77, pp. 4-15.

Ambrosini, M. (1998): "Intereses ocultos: la incorporación de los inmigrantes a la economía informal", Migraciones, $n^{\circ} 4$, pp. 11-151.

Ambrosini, M. (2001): La fatica di integrarsi, Bologna, II Mulino.

Balibar, E (1999): "Le droit de cité ou l'apartheid", en BALIBAR, E. et AL., Sans papiers: l'archaïsme fatal, Paris, La Découverte, pp. 89-116.

Balibar, E. (2003): Nosotros ¿ciudadanos de Europa?. Las fronteras, el estado, el pueblo, Madrid, Tecnos.

Bauböck, R. (2001 a): «Recombinant Citizenship», en KOHLI, M. and WOODWARD, A. (eds.), Inclusions and Exclusions in European Societies, London, Routledge, pp. 38-58.

Bauböck, R. (2001 b): "Cultural Citizenship, Minority Rights and Self-Government", en Aleinikoff, A. and Klusmeyer, D. (eds.), Citizenship Today: Global Perspectives and Practices, Washington, DC, Carnegie Endowment for International Peace, pp. 319-348.
Bauböck, R. (2004): «Cómo transforma la inmigración a la ciudadania: perspectivas internacionales, multinacionales y transnacionales", en Aubarell, G. y Zapata-Barrero, R. Inmigración y procesos de cambio. Europa y el Mediterráneo en el contexto global. Barcelona, Icaria. Antrazyt. IEMed, pp. 177-214.

Blade, K. (2003): Europa en movimiento. Las migraciones desde finales del siglo XVIII hasta nuestros días, Barcelona, Critica.

Bosniak, L. (1992): «Human Rights, State Sovereingnty and the Protection of Undocumented Migrants Under the International Migrants Workers Convention", en International Migration Review, 25, n 4, pp. 737-770.

Braidotti, R. (2003): «La Europa que podria hacernos soñann, Archipiélago, n 58.

Brochmann, G. and Hammar, T. (1999): Mechanisms of Immigration Control. A Comparative Analysis of European Regulation Policies, Oxford and New York, Ed. Berg.

Carpentier, J. y Lebrun, F.(2004): Breve historia de Europa, Barcelona, Altaya.

Carrasco, C. (1999): Mercado de trabajo: os inmigrantes económicos, Colección Observatorio Permanente de la Inmigración, $n^{\circ} 4$, Ministerio de Trabajo y Asuntos Sociales.

Castells, M. y Serra, N. (eds.) (2004): Europa en construcción. Integración. identidades y seguridad, Barcelona, Fundación CIDOB.

Cornelius, W.; Martín, P. and Hollifield, J. (eds.) (2003): Controlling Immigration: A Global Perspective, Stanford, Stanford University Press.

Costa-Lascoux, J. (1999): "L'illusion de la maîtrise, la politique migratoire en trompe-l'oeil», en BALIBAR, E. et AL., Sans papiers: I'archaïsme fatal, Paris, La Découverte, pp. 35-69.

De Bruycker, Ph. (2000): Les régularisations des étrangers illégaux dans I'Union Européenne, Bruxelles, Bruylant.

Del Valle Gálvez, A. (2003): "Control de fronteras y Unión Europea", en Anuario de la Facultad de Derecho de la Universidad Autónoma de Madrid, no 7, pp. 67-92.

ARBOR CLXXXI 713 MAYO-JUNIO [2005] 81-100 ISSN: 0210-1963 
De Lucas, J. (2003 a): «Sobre la integración del fenómeno migratorio en las politicas de cooperación al desarrollon, en Workin Papers Munduan, n० 6, pp. 3-40.

De Lucas, J. (2003 b): Globalización e identidades. Claves políticas y jurídicas, Barcelona, Icaria. Antrazyt.

De Lucas, J. (2004): “Ciudadanía: la jaula de hierro para la integración de los inmigrantes», en Aubarell, G. y Zapata-Barrero, R. Inmigración $y$ procesos de cambio. Europa y el Mediterráneo en el contexto global. Barcelona, Icaria. Antrazyt. IEMed, pp. 215-236.

De Lucas, J. (2005): "Fronteras e identidades. Paradojas del proyecto europeon, en El Punto de Vista de Le Monde Diplomatique, no 2, pp. 28-34.

Ferrajoli, L. (1999): Derechos y Garantías. La ley del más débil, Madrid, Trotta.

Ferrajoli, L. et AL. (2001): Los fundamentos de los derechos fundamentales, Madrid, Trotta.

García España, E. (2003), „Extranjería, delincuencia y legislación penitenciarian, Revista de Derecho Migratorio y Extranjeria, no 4, pp. 43-64.

García España, E. y Rodríguez Candela, J. L. (2002), "Delitos contra los derechos de los extranjeros (318 bis del Código Penal)", Actualidad Penal, no 29.

Gil Araújo, S. (2001): «Migraciones en el espacio europeo ¿Libertad, Justicia y Seguridad?, en Aguirre, M. y González, M., Políticas mundiales, tendencias peligrosas, Anuario CIP 2001, Barcelona, Icaria.

Gil Araújo, S. (2005): «Inmigración e Integración en el espacio europeon, en El Punto de Vista de Le Monde Diplomatique, n 2, pp. 46-49.

Gibney, M. J. (2000): Outside the Protection of the Law: The Situation of Irregular Migrants in Europe, Oxford, Refugee Studies Centre.

Goytisolo, J. y Naïr, S. (2000): El peaje de la vida. Integración o rechazo de la emigración en España, Madrid, Aguilar.

Goody, J. (2004): Islam in Europe, Cambrigde, Polity.

Hayter, T. (2000): Open borders: the case against immigration controls, London, Pluto Press.
Ignatieff, M. (2004): "Males menores", en Claves de Razón Práctica, n 144, pp. 4-11.

Ignatieff, M. (2005): "Democracia y terrorismon, en Claves de Razón Próctica, no 150, pp. 4-13.

Izquierdo Escribano, A. (2003): "La inmigración en Europa: flujos, tendencias y polítican, en Izquierdo Escribano, A. (direc.), Inmigración: mercado de trabajo y protección social en España, Madrid, CES, pp.11-43.

La Calle, A. (2002): «La construcción de la política comunitaria de inmigración", en Pimentel, M. (coord.), Procesos migratorios, economía y personas, Almeria, Instituto de Estudios de Cajamar, pp. 87-104.

Laporta, F. J. (2001): «Inmigración y Respeton, en Claves de Razón Práctica, no 114, pp. 64-68.

Laurenzo Copello, P. (coord.) (2002): Inmigración y derecho penal. Bases para un debate, Valencia, Tirant lo Blanch.

Lynch, E. (2005): "La nueva esclavitud y sus cómplices», en Claves de Razón Práctica, no 149, pp. 64-67.

Martin y Pérez de Nanclares, J. (2002): La inmigración y el asilo en la Unión Europea: hacia un nuevo espacio de libertad, seguridad y justicia, Madrid, Colex.

Martín y Pérez de Nanclares, J. (2003): "La inmigración y el asilo en la Unión Europea: presente y futuron, en Anuario de la Facultad de Derecho de la Universidad Autónoma de Madrid, no 7, pp. 93-118.

Martínez Martínez, R. (2001): Tecnologías de la información, policía y Constitución, Valencia, Tirant lo Blanch.

Martiniello, M. (2003), La Europa de las migraciones. Por una política proactiva de la inmigración, Barcelona, Bellaterra.

Noya Miranda, J. (2003): "Inmigración, mercado de trabajo y Estado de Bienestar. Debate cientifico-político y comparación internacionaln, en Izquierdo Escribano, A. (direc.), Inmigración: mercado de trabajo y protección social en España, Madrid, CES, pp. 45-98.
Olesti Rayo A. (coord.) (2000): Las incertidumbres de la Unión Europea después del Tratado de Ámsterdam, Barcelona, Bosch.

Omicron Osservatorio Milanese sulla Criminalità Organizzata al Nord (2001): "Informe de Investigación: criminalidad e inmigración", Omicron /36 Número especial, Año V, n. 12, pp. 1-36.

Palidda, S. (1999): «Effetti perversi dell'attuale congiuntura delle migrazioni», Diritto, Immigrazione e Cittadinanza, no 1, pp. 28-44.

Phillips, A. (1995): The politics of presence. Oxford, Oxford University Press.

Phillips, A. (1999): "La política de la presencia: la reforma de la representación polítican, en Garcia, S. y LukesS. Ciudadanía: justicia social, identidad y participación, Madrid, Siglo XXI, pp. 235-256.

Ramón Chornet, C. (2005): "La UE y el terrorismo internacionaln, en El Punto de Vista de Le Monde Diplomatique, $n^{\circ} 2$, pp. 60-63.

Roldán Barbero, J. (2000): «La Unión Europea y los nacionales de terceros estados: la posible política de inmigración comunitarian, en Olesti Rayo, A. (coord.), Las incertidumbres de la Unión Europea después del Tratado de Ámsterdam, Barcelona, Bosch, pp. 237-270.

Rotte, R. and Stein, P. (eds.) (2002): Migration Policy and the Economy: International Experiences, Munich, Hans Seidel Stiftung.

Sagarra i Trías, E. (2002): "Un nuevo status de extranjero en Españan, Revista de Derecho de Extranjería, no 1, pp. 89-97.

Sartori, G. (2001): La sociedad multiétnica. Pluralismo, multiculturalismo y extranjeros, Madrid, Taurus.

Sassen, S. (2001): ¿Perdiendo el control? La soberanía en al era de la globalización, Barcelona, Bellaterra.

Sciortino, G. (1997): «Troppo buoni? La politica migratoria tra controlli alle frontiere e gestione del mercato del lavoron, en Reyneri, E.; Minardi, E. e Scidá, G., Immigrati e lavoro in Italia, Milano, FrancoAngeli, pp. 50-84. 
Sciortino, G. (1999): «Le politiche di controllo nel contesto europeon, Diritto, Immigrazione e Cittadinanza, $n^{\circ} 3$, pp. 21-40.

Solanes, A. (2003): "La irregularidad que $<$ genera $>$ la ley de extranjería. Un factor a tener en cuenta en una futura reforman, Revista de Derecho Migratorio y Extranjería, no 4, pp. 125-139.

Solanes, A. y Cardona, M. B. (2005): Protección de datos personales y derechos de los extranjeros inmigrantes, Valencia, Tirant lo Blanch.

Tandonnet, A, M. (2001): Le grand bazar ou l'Europe face à l'immigration, Paris, L'Harmattan.

Terray, E. (1999): "Le travail des étrangers en situation irrégulière ou la délocalisation sur place», en Balibar, E. et AL., Sans papiers: l'archaïsme fatal, Paris, La Découverte, pp. 9-34.

Trinidad García, Ma . L. (2002), "Los acuerdos bilaterales concluidos por España: un complejo instrumento para unos resultados escasos", en García Castaño, J. y Muriel López, C., La Inmigración en España. Contextos y alternativas, Ponencias del III Congreso sobre la Inmigración en España, Granada, Laboratorio de Estudios Internculturales, pp. 494-505.

Todorov, T. (2003): Le nouveau Désordre Mondial. Réflexions d'un Européen, Paris, Laffont.

Tornos Cubillo, A. (2004): «Nuevos movimientos migratorios en una Unión Europea ampliadan, Migraciones, $n^{\circ} 16$, pp. 237-254.

Walzer, M. (2004): "Las emergencias y las excusas al terrorismo", en Claves de Razón Próctica, n 143, pp. 10-20.

Wihtol de Wenden, C. (1999 a): La ciudadanía europea, Barcelona, Bellaterra.

Wihtol de Wenden, C. (1999 b): L'immigration en Europe, Nancy, La documentation Française.

Wihtol de Wenden, C. (2000): ¿Hay que abrir las fronteras?, Barcelona, Bellaterra.

Wihtol de Wenden, C. (2003): "Pour le droit de vote des immigrés aux élections municipales", en Guillot, J. (dir.). Immigració i poders locals. Ciutats i Persones. Barcelona, Institut de Ciències Politiques i Socials, pp. 251-258.
Wihtol de Wenden, C. and Mohsen-Finan, K. (eds) (2001): Nouvelles citoyennetés: Réfugées et sans-papiers dans l'espace européen, Paris, IFRI.

Zagrebelsky, G. (1997): El derecho dúctil. Ley, derechos, justicia, Madrid, Trotta.

Zapata-Barrero, R. (2004): Multitculturalidad e Inmigración, Madrid, Sintesis.

Zincone, G., (2004): "Procesos migratorios y transformación de los derechos de ciudadanía", en Aubarell, G. y Zapata-Barrero, R. Inmigración y procesos de cambio. Europa y el Mediterráneo en el contexto global. Barcelona, Icaria. Antrazyt. IEMed, pp. 237-259. 